\title{
The effect of nicotine on the mechanical properties of mesenchymal stem cells
}

This article was published in the following Dove Press journal:

Cell Health and Cytoskeleton

27 March 2012

Number of times this article has been viewed

\author{
Juan P Ruiz ${ }^{1,2}$ \\ Daniel Pelaez ${ }^{1,2}$ \\ Janice Dias' \\ Noël M Ziebarth' \\ Herman S Cheung ${ }^{1,2}$ \\ 'Department of Biomedical \\ Engineering, University of Miami \\ College of Engineering, Coral \\ Gables, FL, USA; ${ }^{2}$ Research Service \\ and Geriatrics Research, Education, \\ and Clinical Center, Veterans Affairs \\ Medical Center, Miami, FL, USA
}

\section{Video abstract}

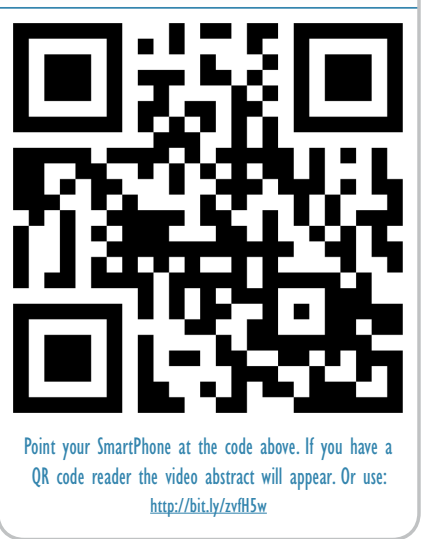

Correspondence: Herman S Cheung Department of Biomedical Engineering, University of Miami, McArthur Annex Room 214, I25I Memorial Drive, Coral Gables, FL 33I46, USA

Tel +I 3052844466

Email hcheung@med.miami.edu
Purpose: To measure the elasticity of the nucleus and cytoplasm of human mesenchymal stem cells (MSCs) as well as changes brought about by exposure to nicotine in vitro.

Methods: MSCs were synchronized to the $\mathrm{G}_{0}$ stage of the cell cycle through serum deprivation techniques. The cells were then treated with medium containing nicotine $(0.1 \mu \mathrm{M}, 0.5 \mu \mathrm{M}$, and $1 \mu \mathrm{M})$. Atomic force microscopy was then used to measure the Young's modulus of both the nucleus and cytoplasm of these cells.

Results: For both unsynchronized and synchronized cells, the nucleus was softer than the cytoplasm, although this difference was not found to be statistically significant. The nucleus of cells treated with nicotine was significantly stiffer than the control for all concentrations. The cytoplasm was significantly stiffer in nicotine-treated cells than in control cells for the $0.5 \mu \mathrm{M}$ and $1.0 \mu \mathrm{M}$ concentrations only.

Conclusions: The results of this study could suggest that nicotine affects the biophysical properties of human MSCs in a dose-dependent manner, which may render the cells less responsive to mechanoinduction and other physical stimuli.

Keywords: atomic force microscopy, elasticity, mesenchymal stem cells, nicotine

\section{Introduction}

Mesenchymal stem cells (MSCs) are fibroblast-like cells, which reside in the bone marrow, adipose tissue, skin, and periosteum of vertebrate animals, including humans. MSCs have the capacity to differentiate into cartilage, bone, fat, tendon, and muscle. ${ }^{1}$ MSCs represent a renewable source of cells that could be used for tissue regeneration or reconstruction of damaged musculoskeletal tissue by cellular transplantation. However, a person's habits and lifestyle choices may affect the effectiveness of such therapies. In fact, many of the patients in need of these cellular therapies, such as those who smoke, could potentially have niche environments in their body that will render these stem cell populations ineffective posttransplantation. High levels of cigarette chemicals in the blood of smokers, for example, could potentially damage the transplanted MSCs and render them ineffective. It is therefore important to investigate the effect of such habits on stem cell populations.

Cigarette smoking is a well-known risk factor for a number of diseases, including cardiopulmonary diseases, in the adult population. ${ }^{2}$ Cigarette smoke consists of a large number of chemicals, including nicotine, aromatic hydrocarbons, hydrogen cyanide, and aldehydes, among others. ${ }^{3}$ Nicotine is the most prevalent chemical in cigarettes and is absorbed rapidly into the arterial circulation and tissues throughout the body. ${ }^{4}$ Nicotine has also been shown to negatively impact human embryonic 
stem cells and their development by altering the cell's morphology in vitro and downregulating the expression of certain pluripotency markers, including Oct3/4, Tra-1-81, and Tra-1-60.5 Nicotine induces angiogenesis via nicotine acetylcholine receptors; ${ }^{6,7}$ these receptors are present in both neurons and other cell types. ${ }^{7}$ Nicotine has been shown to delay skeletal healing by as much as $60 \%$ following fractures by influencing gene expression critical to the bone-healing process. ${ }^{78}$ However, the effects of nicotine on adult MSCs remain largely unexplored.

Although much attention has been focused on the influence of bioreactive factors such as cytokines and chemokines upon MSC differentiation and growth, the effects of mechanical stimuli on these cells, in terms of their differentiation and phenotypic maintenance capabilities, are still poorly understood. It has been shown that the biophysical properties of MSCs determine the commitment of these cells to different lineages during differentiation. ${ }^{9}$ Recently, we reported that dynamic compressive loading stimulated viability and chondrogenic differentiation of MSCs in the absence of exogenous cytokines. ${ }^{10-12}$ Compressive loading induced endogenous transforming growth factor (TGF)- $\beta 1$ as well as TGF- $\beta$ receptor gene expression of MSCs, suggesting that dynamic compression might induce chondrogenesis of these cells via the TGF- $\beta$ signal pathway. ${ }^{10}$ Subsequently, we demonstrated temporal expression patterns of early response and chondrogenic genes (c-fos, c-jun, TGF- $\beta$, TGF- $\beta$ receptor- 1 and -II, Sox9, and type II collagen) and induction of their corresponding proteins in MSCs stimulated by dynamic compressive loading. ${ }^{11}$

During compression-induced chondrogenesis, MSCs undergo significant deformation, and our preliminary data indicate that compressive loading exerts its chondrogenic effect by activating the P42/44 mitogen-activated protein kinases signal pathways. These cells are therefore able to take mechanical forces and translate them into chemical signals that control gene expression, a phenomenon known as mechanotransduction. It has been reported that the mechanical properties of stem cells play a key role in their potential to differentiate. ${ }^{13}$ Stiffer cells are unable to respond to the external mechanical stimuli necessary to drive differentiation into various cells types. ${ }^{14,15}$ In fact, the mechanical properties of stem cells, which dictate their response to mechanical stimuli, can actually be used as a biomarker to measure multipotency. ${ }^{13,16,17}$ In order to assess the mechanical properties of stem cells, previous studies have measured the Young's modulus of elasticity using micropipette aspiration $^{18-20}$ and atomic force microscopy (AFM). ${ }^{14,15,21-27}$
Micropipette aspiration measures the elasticity of free floating cells, while AFM measures the elasticity of cells attached to a substrate, usually tissue culture plastic. Previous AFM studies on MSCs, however, use a spherical probe that is 5-10 $\mu$ in radius, which will measure an average Young's modulus of the whole cell. Because the nucleus plays an important role in a cell's mechanical properties, ${ }^{28}$ it is important to explore the mechanical properties of both the nuclear and cytoplasmic regions. Therefore, the first purpose of this project was to quantify the mechanical properties of the nucleus and cytoplasm of MSCs independently. The second objective of this study was to explore the effects of nicotine on this biophysical property of MSCs.

\section{Materials and methods Cell culture}

\section{Mesenchymal stem cells}

MSCs were commercially obtained from ScienceCell Research Laboratories (Cat \#7500; ScienceCell Research Laboratories, Carlsbad, CA) as CD73-, CD90-, and CD105positive cells capable of adipogenic, chondrogenic, and osteogenic differentiation. For all experiments, MSCs were used at either passage 2 or 3 .

\section{Plating and synchronization}

Cells were plated at 10,000 cells $/ \mathrm{cm}^{2}$ in high-glucose Dulbecco's modified Eagle's medium (DMEM; Invitrogen, Carlsbad, CA) supplemented with 10\% (v/v) fetal bovine serum (Invitrogen), $10 \mu \mathrm{g} / \mathrm{mL}$ and $10 \mu \mathrm{g} / \mathrm{mL}$ penicillin/ streptomycin, respectively (Invitrogen), and $0.25 \mu \mathrm{g} / \mathrm{mL}$ amphotericin B (Thermo Scientific, Waltham, MA) on $35 \mathrm{~mm} \times 10 \mathrm{~mm}$ tissue culture dishes (Sarstedt, Newton, NC). The cells were left in the incubator at $37^{\circ} \mathrm{C}$ and $5 \% \mathrm{CO}_{2}$ for 24 hours to allow for cell attachment. Nonadherent cells were washed off during the first medium change 24 hours after initial plating. The desired confluence of $40 \%-50 \%$ was reached after approximately 48 hours in the incubator. The plates were then washed with phosphate buffered saline solution twice and placed in serum-deprived high-glucose DMEM supplemented with $1 \%(\mathrm{v} / \mathrm{v})$ penicillin/streptomycin. The cells were placed in the incubator for an additional 72 hours to allow the cells to synchronize to the $\mathrm{G}_{0}$ phase of the cell cycle. Unsynchronized control cells while testing synchronization efficacy were left in regular culture medium for the 72-hour period.

\section{Nicotine treatment}

In order to test the effects of nicotine on MSCs cultured in vitro, cells were plated out as described previously, and 
plates were randomly separated into four treatment groups. The control group was synchronized as described previously and, following the 72-hour synchronization period, starvation medium was removed and replaced with high-glucose DMEM containing 10\% fetal bovine serum, 1\% penicillin/ streptomycin, and $0.1 \%$ amphoteracin $\mathrm{B}$. The other three groups were also synchronized, but the starvation medium was then replaced by regular medium as described previously, supplemented with different concentrations of nicotine (nicotine 99\% [TLC], liquid, N0267; Sigma-Aldrich, St Louis, MO): $0.1 \mu \mathrm{M}, 0.5 \mu \mathrm{M}$, and $1.0 \mu \mathrm{M} .^{29-31}$ The cells were left in the incubator for 48 hours with the nicotine medium before being subjected to AFM testing (Figure 1).

\section{Elasticity measurements}

A custom-built nanoindenter based on the design of commercial atomic force microscopes has been developed to measure mechanical properties. ${ }^{32-34}$ A pyramidal AFM cantilever tip $(0.01 \mathrm{~N} / \mathrm{m}$, silicon nitride, $20 \mathrm{~nm}$ tip radius, MLCT series; Bruker AFM Probes, Camarillo, CA) was used to indent the cells.

After the cells were cultured as described previously, the Petri dish containing the cells was placed under the holder containing the AFM cantilever. The location of the cantilever on the sample was observed using the $20 \times$ microscope objective connected to a camera beneath the sample. This enabled precise positioning of the cantilever above either the cytoplasmic or the nuclear region of the cell. The tip was lowered until it was just touching the surface of the cell (Figure 2). The tip was then lowered using the piezoelectric control so that it was probing the cell. The measurements were conducted using a cantilever approach with a retraction speed of $15 \mu \mathrm{m} / \mathrm{s}$ and a maximal indentation force of $60 \mathrm{nN}$. The voltage detected at the photodiode due to deflection of the cantilever was recorded as a function of piezoelectric displacement. These recordings were repeated at least 15 times per cell, and at least ten cells per nicotine

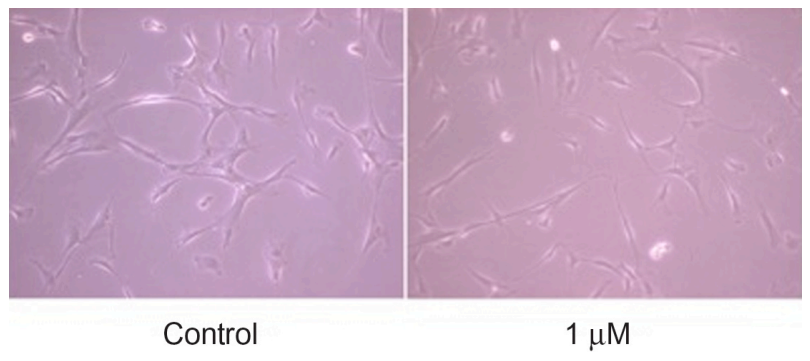

Figure I Phase-contrast images of mesenchymal stem cells in culture. Images were taken of the control cells as well as of those subjected to the highest concentration of nicotine $(\mathrm{I} \mu \mathrm{M})$.

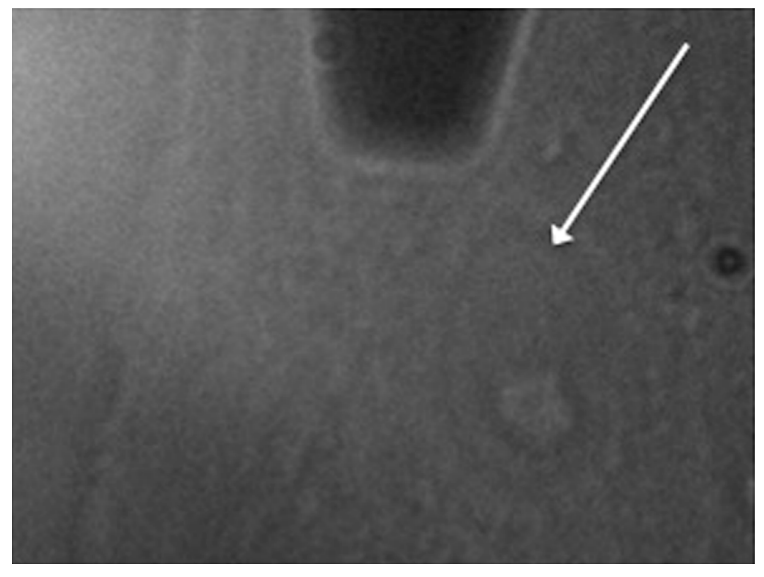

Figure 2 Image showing view (from bottom) of plate, with atomic force microscopy cantilever placed over the cytoplasm of the mesenchymal stem cell. The image is taken by a camera through a $20 \times$ objective positioned underneath the culture dish. The nucleus is signaled by the arrow.

concentration were measured. The experiments were repeated for both the cytoplasmic and nuclear regions of each cell. All experiments were performed at room temperature while the cells remained submerged in DMEM.

\section{Data analysis}

The data analysis procedure for the AFM measurements has been described previously. ${ }^{32}$ The photodiode voltage versus piezoelectric displacement recorded during the measurement scans was converted to force versus indentation after accounting for the cantilever spring constant and its behavior when probing a rigid substrate. The force versus indentation relationship was analyzed using the Bilodeau ${ }^{35}$ model for a pyramidal indenter:

$$
F=\frac{E \tan \alpha}{\sqrt{2}\left(1-v^{2}\right)} D^{2}
$$

where $F[\mathrm{~N}]$ is the measured force, $E\left[\mathrm{~N} / \mathrm{m}^{2}\right]$ is Young's modulus, $v$ is Poisson's ratio (assumed to be 0.5 ), $\alpha$ is the pyramidal semiangle $\left(15^{\circ}\right)$, and $D$ is the measured indentation. The determination of Young's modulus was carried out using custom-developed Matlab software. Each curve fit was verified visually. Because at least 15 measurements were performed for each position on the cell, the average of these values was then used as the modulus for that position.

All data and graphs represent mean values plus or minus standard error of the mean. All data sets were tested for significance using $t$-tests (one-tailed, two-sample unequal variance). Studies that tested for significance in differences of standard deviation were done using an $f$-test with n-1 degrees 
of freedom. Statistical significance was determined by $P$-values lower than 0.05 .

\section{Viability and cytoskeleton staining}

In order to test for cell viability post-treatment, a group of treatment and control cells were treated with $4 \mu \mathrm{M}$ calcein (calcein-AM, C1430; Invitrogen) and $4 \mu \mathrm{M}$ ethidium homodimer (ethidium homodimer B, 46043; Sigma-Aldrich), then imaged using fluorescence microscopy to view live and dead cells. Similarly, a group of treatment and control cells were first fixed in $10 \%$ formalin solution for 10 minutes, then rinsed once with phosphate buffered saline, and their f-actin stained with phalloidin (AlexaFluor 568 phalloidin, A12380; Invitrogen). The cells were then mounted with Vectashield (Vectashield mounting medium with DAPI; Vector Labs, Burlingame, CA) and imaged with fluorescence microscopy.

\section{Results}

\section{Elasticity of nucleus and cytoplasm}

A total of $10 \mathrm{MSCs}$ cultured as described previously, but without synchronization to the $\mathrm{G}_{0}$ phase, were measured using AFM. The elasticity measurements were performed in the area of the cell cytoplasm and nucleus for all ten cells. The elasticity was measured to be $23.0 \mathrm{kPa} \pm 4.7 \mathrm{kPa}$ for the cytoplasm and $13.5 \mathrm{kPa} \pm 4.0 \mathrm{kPa}$ for the nucleus (Figure 3 ). The initial measurements of elasticity yielded large betweensample variability (standard deviation/average). It was hypothesized that the high variability could be due to cells being in different phases of the cell cycle. In an attempt to confirm this hypothesis and reduce between-sample variability, all cells were synchronized to the same phase of the cell cycle using the starvation protocol described previously. The elasticity of ten synchronized cells was then measured in the area of the cytoplasm and the nucleus. The elasticity was found to be $15.4 \mathrm{kPa} \pm 1.9 \mathrm{kPa}$ for the cytoplasm and $11.9 \mathrm{kPa} \pm 2.2 \mathrm{kPa}$ for the nucleus (Figure 3). There was a significant decrease in the variability of the cytoplasm ( $P=0.02)$ but not the nucleus $(P=0.11)$ of synchronized cells compared with the unsynchronized cells.

\section{Elasticity of cells treated with nicotine}

To test the effect of nicotine exposure on the biophysical properties of the cell, four treatment groups were plated, cultured, and synchronized as described previously. After synchronization, cells were treated with regular medium for the control group and with the three different concentrations of nicotine for the treatment groups $(0.1 \mu \mathrm{M}, 0.5 \mu \mathrm{M}$, and $1.0 \mu \mathrm{M})$.

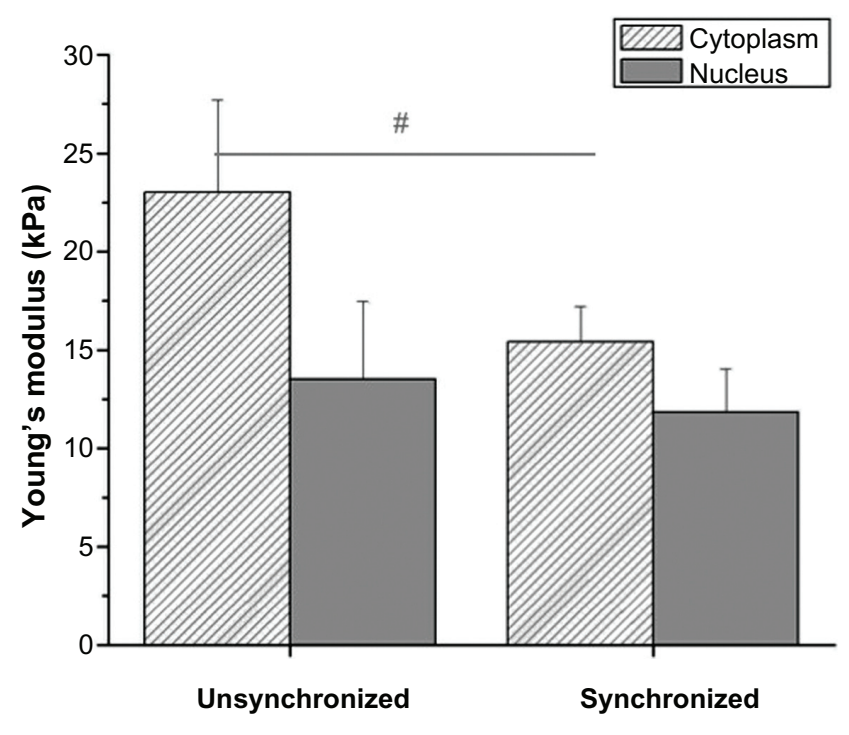

Figure 3 Average values for the elasticity of cytoplasmic and nuclear regions of the mesenchymal stem cells.

Note: \#Variability was significantly decreased with synchronization, for cytoplasm measurements only.

The elasticity of ten cells of each group was measured using AFM. As the concentration of nicotine increased, the Young's modulus, and therefore stiffness, of the MSCs increased, both for nucleus and cytoplasm values. The Young's modulus of the nucleus of cells treated with nicotine was significantly different from that of the control $(4.70 \mathrm{kPa} \pm 0.83 \mathrm{kPa})$ for all concentrations of nicotine, with values of $7.05 \mathrm{kPa} \pm 0.76 \mathrm{kPa}$ $(P=0.03), 16.41 \mathrm{kPa} \pm 4.06 \mathrm{kPa}(P=0.009)$, and $17.52 \mathrm{kPa} \pm 3.74 \mathrm{kPa}(P=0.004)$, respectively. The measured Young's modulus for the cytoplasm of cells treated with nicotine was significantly different from the control $(9.07 \mathrm{kPa} \pm 2.13 \mathrm{kPa})$ for the cells treated with $0.5 \mu \mathrm{M}$ and $1.0 \mu \mathrm{M}$ nicotine concentrations only with values at $25.49 \mathrm{kPa} \pm 3.64 \mathrm{kPa}(P<0.001)$ and $15.55 \mathrm{kPa} \pm 2.74 \mathrm{kPa}$ $(P=0.05)$, respectively (Figure 4$)$.

\section{Viability assay and cytoskeletal staining}

A calcein and ethidium homodimer costain was used at the end of the nicotine treatments. No difference was noted in cell death across treatments (Figure 5).

Cytoskeletal staining of f-actin at the end of the treatments revealed the cytoskeletal protein concentration and arrangement following treatments (Figure 5). We could not discern any significant difference in f-actin conformation or concentration across treatments.

\section{Discussion}

Initial experiments to measure the elasticity of control MSCs showed extremely high between-sample variability. 


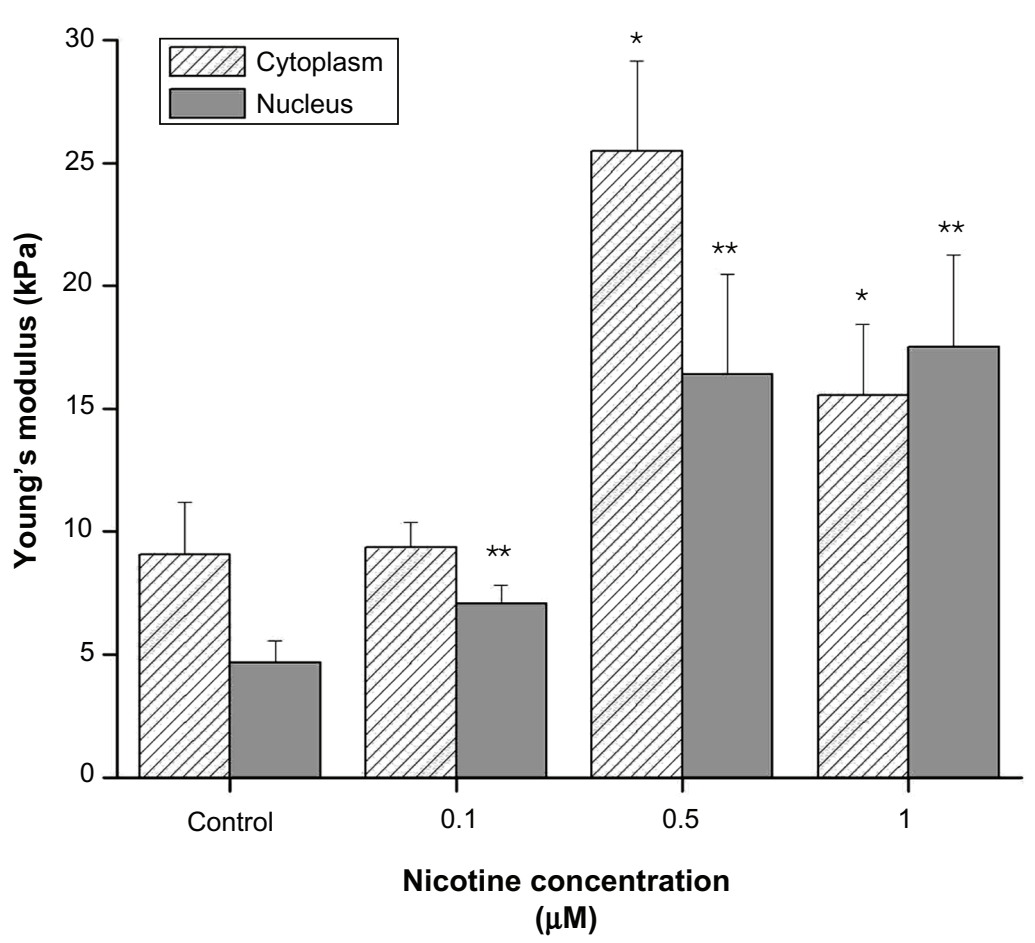

Figure 4 Average values for the elasticity of cytoplasmic and nuclear regions of the mesenchymal stem cells treated with different concentrations of nicotine. For both regions of the cell, the elasticity decreases (Young's modulus increases) with increasing nicotine concentration.

Notes: *Statistical significance compared with cytoplasm control; **statistical significance compared with nucleus control.

Similar studies in the literature using AFM had similar high variability. ${ }^{14,15,21}$ We hypothesized that individual cells in different stages of the cell cycle were causing high variability in the elasticity measurements. We tested synchronizing the cells using serum deprivation techniques as a way to decrease between-sample variability by reducing the effect of different stages of the cell cycle on our elasticity measurements. There was a decrease in the variability of our data sets. For this reason, all our future studies were done on cells that were synchronized using the same protocol.
The aim of the first part of our study was to find the Young's modulus of the cytoplasmic and nuclear regions of MSCs separately. Our study found that there is no significant difference between the Young's modulus of the cytoplasm and the nucleus. In a previous study ${ }^{28}$ it was reported that the nucleus is an important structure that determines the overall mechanical properties of stem cells. Our results support this evidence, because the range of values for the nucleus and cytoplasm was comparable for synchronized cells.

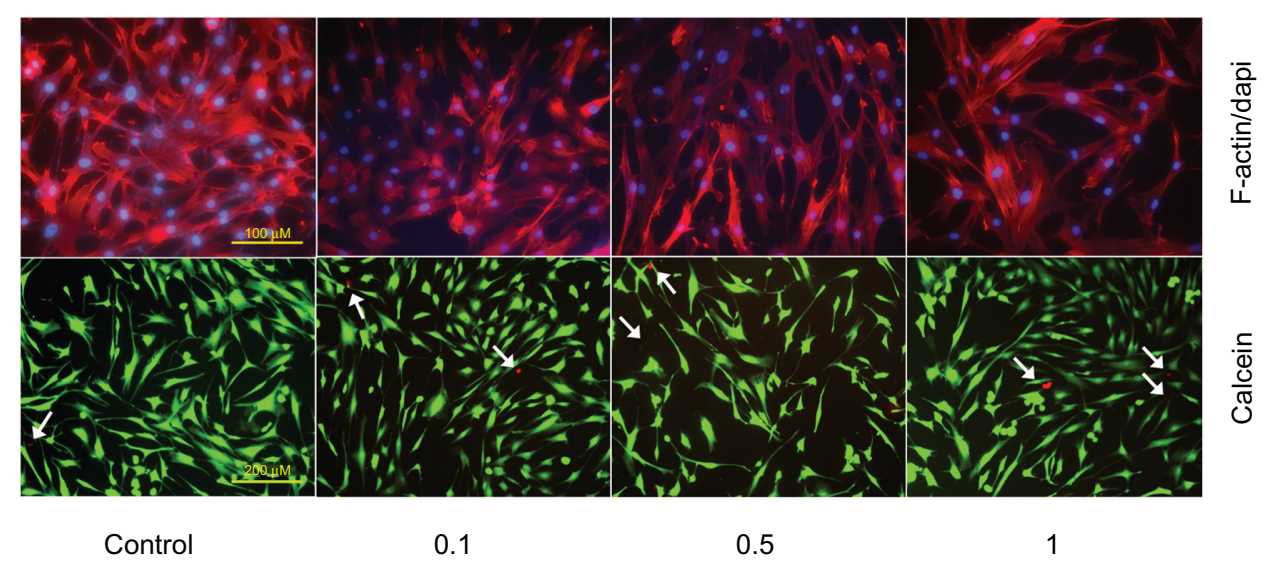

Figure 5 Viability and cytoskeletal staining for mesenchymal stem cells across treatment. Top panel: cells were stained with fluorescent phalloidin and with DAPI stain. Bottom panel: cells were stained with calcein to measure viability and with ethidium homodimer to measure cell death. 
It is interesting also to note that our values for the Young's modulus of MSCs are higher than those of previous studies that performed similar tests with AFM, which have values that range from $2.5 \mathrm{kPa}$ to $5.0 \mathrm{kPa}^{1,4,15,21}$ compared with our values, which range from $11.9 \mathrm{kPa}$ to $15.4 \mathrm{kPa}$, depending on whether cells were measured on the cytoplasm or nucleus. These differences can most likely be attributed to variations in methodology. Previous studies have used a spherical tip $5 \mu$ or $10 \mu$ in diameter, thereby limiting the possibility of accurately determining measurement site within the cell. We used a more precise pyramidal tip $40 \mathrm{~nm}$ in diameter to enable measurement of the cytoplasm and nucleus separately, assessed by microscopic observations of tip placement. In addition, the spring constant of the cantilever used in this study was significantly lower than that used in previous studies. A larger spring constant will subsequently result in a higher degree of cell indentation. Due to these differences in size and stiffness of the cantilever, our measurements were most likely more susceptible to local elastic variations in the cell membrane or cytoskeleton. In addition, previous studies were performed at a higher speed of indentation. Due to the intrinsic viscoelastic nature of the MSCs, indentation speed will affect the final measurements obtained.

Furthermore, all of the studies done on the physical and mechanical properties of MSCs using AFM yielded higher Young's modulus values than studies done using micropipette aspiration, which usually provide values ranging from $0.4 \mathrm{kPa}$ to $0.9 \mathrm{kPa} \cdot{ }^{19,20}$ Such differences lie in the mechanics of the test themselves, as AFM studies measure cells attached to a substrate while micropipette aspiration studies measure the Young's modulus of cells that are free floating. Therefore, micropipette aspiration studies are more representative of the physical properties of circulating MSCs, while AFM studies are more representative of the physical properties of MSCs within their bone marrow niche or after they have extravasated to sites of injury.

The second goal of these experiments was to quantify the effect that nicotine, one of the major chemicals found in cigarette smoke, had on the physical properties of MSCs in vitro. Our study found that certain levels of nicotine in the culture medium of MSCs that fall within the range of levels found in the serum and saliva of smokers ${ }^{29-31}$ led to MSCs with higher Young's moduli, both in the cytoplasmic and nuclear regions of the cells. Although a nicotine concentration of $0.1 \mu \mathrm{M}$ did not lead to a significant increase in the Young's modulus of these cells, concentrations of $0.5 \mu \mathrm{M}$ and $1.0 \mu \mathrm{M}$ yielded cells with significantly higher Young's moduli than the control group, in both cytoplasmic and nuclear regions.
The results of this proof-of-principle study show that nicotine increases the stiffness of MSCs in vitro in a dosedependent manner. The exposure was done in the short time span of 48 hours. An increase in stiffness due to nicotine treatment was seen, however. This is relevant for regenerative medicine applications where MSCs are injected into the blood or target organs, as studies have shown that MSCs remain in the body for more than 48 hours after infusion. ${ }^{36}$ This could suggest that MSC therapies could be less effective on people who smoke, as infused MSCs will be exposed to high nicotine levels in their blood, limiting their therapeutic potential. Studies are being performed on longer-term effects of nicotine exposure, as well as the effect of nicotine in combination with other smoking derivatives such as benzopyrenes. Further studies are also needed to discover whether this stiffening effect by nicotine is a reversible one, as well as measure the Young's modulus of different populations of MSCs, including those circulating in the blood of smokers and nonsmokers.

In summary, we found that there is no significant difference in the stiffness of the nucleus and cytoplasm of MSCs. However, the data suggested that synchronizing the cells through serum starvation reduces the between-sample variability of the data. Moreover, increasing concentration of nicotine increases the Young's modulus of both the cytoplasm and nucleus of MSCs.

\section{Disclosures}

This study was supported in part by a National Institute of Health Initiative for Maximizing Student Development Grant (JPR and JD), a VA Merit Review Grant (HSC), and a Senior VA Research Career Scientist Award (HSC). It was presented in part at the Biomedical Engineering Society 2010 meeting.

\section{References}

1. O'Keefe RJ. Summary. Cell therapies for orthopedic applications. $J$ Musculoskelet Neuronal Interact. 2005;5(4):367-368.

2. Erhardt L. Cigarette smoking: an undertreated risk factor for cardiovascular disease. Atherosclerosis. 2009;205(1):23-32.

3. Villablanca AC, McDonald JM, Rutledge JC. Clin Chest Med. 2000; 21(1):159-172.

4. Benowitz NL. Pharmacology of nicotine: addiction and therapeutics. Annu Rev Pharmacol Toxicol. 1996;36:597-613.

5. Zdravkovic T, Genbacev O, LaRocque N, McMaster M, Fisher S. Human embryonic stem cells as a model system for studying the effects of smoke exposure on the embryo. Reprod Toxicol. 2008;26:86-93.

6. Wang Y, Pereira EF, Maus AD, et al. Human bronchial epithelial and endothelial cells express alpha7 nicotinic acetylcholine receptors. Mol Pharmacol. 2001;60(6):1201-1209.

7. Ma L, Sham MH, Zheng LW, Cheung LK. Influence of low-dose nicotine on bone healing. J Trauma. 2011;70(6):E117-E121.

8. Zheng LW, Ma L, Cheung LK. Changes in blood perfusion and bone healing induced by nicotine during distraction osteogenesis. Bone. 2008;43: 355-361. 
9. McBeath R, Pirone D, Nelson CM, Bhadriraju K, Chen CS. Cell shape, cytoskeletal tension, and RhoA regulate stem cell lineage commitment. Dev Cell. 2004;6:483-495.

10. Huang CY, Hagar KL, Frost LE, Sun Y, Cheung HS. Effects of cyclic compressive loading on chondrogenesis of rabbit bone-marrow derived mesenchymal stem cells. Stem Cells. 2004;22(3):313-323.

11. Huang CY, Reuben PM, Cheung HS. Temporal expression patterns and corresponding protein inductions of early responsive genes in rabbit bone marrow-derived mesenchymal stem cells under cyclic compressive loading. Stem Cells. 2005;23(8):1113-1121.

12. Pelaez D, Huang CY, Cheung HS. Dynamic compression maintains viability and induces chondrogenesis of human MSC in fibrin gel scaffolds. Stem Cell Dev. 2009;18(1):93-102.

13. Daniels BR, Hale CM, Khatau SB, et al. Differences in the microrheology of human embryonic stem cells and human induced pluripotent stem cells. Biophys J. 2010;99(11):3563-3570.

14. Titushkin I, Cho M. Modulation of cellular mechanics during osteogenic differentiation of human mesenchymal stem cells. Biophys J. 2007;93(10):3693-3702.

15. Titushkin IA, Cho MR. Controlling cellular biomechanics of human mesenchymal stem cells. Conf Proc IEEE Eng Med Biol Soc. 2009: 2090-2093.

16. Chowdhury F, Na S, Li D, et al. Material properties of the cell dictate stress-induced spreading and differentiation in embryonic stem cells. Nature Mater. 2010;9:82-88.

17. Hammerick KE, Huang Z, Sun N, et al. Elastic properties of induced pluripotent stem cells. Tissue Eng Part A. 2011;17(3-4):495-502.

18. Pan W, Petersen E, Cai N, et al. Viscoelastic properties of human mesenchymal stem cells. Conf Proc IEEE Eng Med Biol Soc. 2005: 4854-4857.

19. Tan SC, Pan WX, Ma G, Cai N, Leong KW, Liao K. Viscoelastic behavior of human mesenchymal stem cells. BMC Cell Biol. 2008;9:40.

20. Yu H, Ta CY, Leong WS, Tan SC, Liao K, Tan LP. Mechanical behavior of human mesenchymal stem cells during adipogenic and osteogenic differentiation. Biochem Biophys Res Commun. 2010;393(1):150-155.

21. Darling EM, Zauscher S, Guilak F. Viscoelastic properties of zonal articular chondrocytes measured by atomic force microscopy. Osteoarthritis Cartilage. 2006;14(6):571-579.

22. Chen Q, Xiao P, Chen JN, et al. AFM studies of cellular mechanics during osteogenic differentiation of human amniotic fluid-derived stem cells. Anal Sci. 2010;26(10):1033-1037.
23. Docheva D, Padula D, Popov C, Mutschler W, Clausen-Schaumann H, Schieker M. Researching into the cellular shape, volume and elasticity of mesenchymal stem cells, osteoblasts and osteosarcoma cells by atomic force microscopy. J Cell Mol Med. 2008;12(2):537-552.

24. Maloney JM, Nikova D, Lautenschläger F, et al. Mesenchymal stem cell mechanics from the attached to the suspended state. Biophys $J$. 2010;99(8):2479-2487.

25. Pillarisetti A, Ladjal H, Ferreira A, Keefer C, Desai JP. Mechanical characterization of mouse embryonic stem cells. Conf Proc IEEE Eng Med Biol Soc. 2009:1176-1179.

26. Yim EK, Darling EM, Kulangara K, Guilak F, Leong KW. Nanotopography-induced changes in focal adhesions, cytoskeletal organization, and mechanical properties of human mesenchymal stem cells. Biomaterials. 2010;31(6):1299-1306.

27. Yourek G, Hussain MA, Mao JJ. Cytoskeletal changes of mesenchymal stem cells during differentiation. ASAIO J. 2007;53(2):219-228.

28. Ribeiro AS, Dahl KN. The nucleus as a central structure in defining the mechanical properties of stem cells. Conf Proc IEEE Eng Med Biol Soc. 2010;1:831-834.

29. Giannopoulou C, Geinoz A, Cimasoni G. Effects of nicotine on periodontal ligament fibroblasts in vitro. J Clin Periodontal. 1999;26: 49-55.

30. Benowitz NL, Jacob P. Daily intake of nicotine during cigarette smoking. Clin Pharmacol Ther. 1984;35(4):499-504.

31. Brucket E, Jacob N, Lamaire L, Truffert J, Percheron F, Gennes JL. Relationship between smoking status and serum lipids in a hyperlipidemic populations and analysis of possible confounding factors. Clin Chem. 1992;38(9):1698-1705.

32. Ziebarth NM, Wojcikiewicz EP, Manns F, Moy VT, Parel JM. Atomic force microscopy measurements of lens elasticity in monkey eyes. Mol Vis. 2007;13:504-510.

33. Binnig G, Quate CF, Gerber C. Atomic force microscope. Phys Rev Lett. 1986;56(9):930-933.

34. Tománek D, Overney G, Miyazaki H, Mahanti SD, Güntherodt HJ. Theory for the Atomic Force Microscopy of deformable surfaces. Phys Rev Lett. 1989;63(8):876-879.

35. Bilodeau GG. Regular pyramid punch problem. J Appl Mech. 1992; 59(3):519-524.

36. Gao J, Dennis JE, Muzic RF, Lundberg M, Caplan A. The dynamic in vivo distribution of bone marrow-derived mesenchymal stem cells after infusion. Cells Tissues Organs. 2001;169(1):12-20.
Cell Health and Cytoskeleton

\section{Publish your work in this journal}

Cell Health and Cytoskeleton is an international, peer-reviewed open access journal focusing on all aspects of cell structure and function contributing to normal physiology and cell health and exploring the pathogenesis of cell dysfunction leading to adverse conditions and disease in the organism. The journal welcomes papers covering original research,

\section{Dovepress}

basic science, reviews and evaluations, guidelines, expert opinion and commentary, case reports and extended reports. The manuscript management system is completely online and includes a very quick and fair peerreview system, which is all easy to use. Visit http://www.dovepress.com/ testimonials.php to read real quotes from published authors. 